\title{
Conceptualizing Community Engagement: Starting a Campus-Wide Dialogue
}

\author{
Anthony Starke, Keristiena Shenouda, and Deborah Smith-Howell
}

\begin{abstract}
Institutions of higher education are increasingly compelled to produce evidence that illustrates their contribution to society. In this age of demonstrating value, self-assessment is critical for urban and metropolitan universities. This study will explore the design and implementation of a landscape analysis - phase one of an in-depth self-assessment - at the University of Nebraska at Omaha (UNO). This process is intended to help universities gain a better understanding of how community engagement is conceptualized and institutionalized on their campus. A thorough understanding of the meaning of, and linguistics associated with, community engagement is imperative for the creation of community engagement measurement and assessment mechanisms. The authors will share the methodology and key findings, which include the discovery of domains of community engagement and acknowledgement of a spectrum of engagement.
\end{abstract}

\section{Keywords}

Landscape analysis; interviews; data collection

\section{Introduction}

As Nebraska's metropolitan university, the University of Nebraska at Omaha (UNO) has a longstanding tradition of engaging with its community. UNO's mission highlights its desire to develop and maintain "significant relationships with our community" (University of Nebraska at Omaha, 2012). In order to actualize that vision, the campus leadership has established community engagement as a university-wide, strategic goal.

Though slight variations in formal definitions may occur, it has been widely accepted that community engagement in higher education consists of reciprocal and mutually beneficial partnerships between institutions of higher education and their community. The advent of the Carnegie community-engagement classification solidified the following definition as the industry standard:

Community engagement describes collaboration between institutions of higher education and their larger communities (local, regional/state, national, global) for the mutually beneficial exchange of knowledge and resources in a context of partnership and reciprocity (New England Research Center for Higher Education, n.d.).

While UNO subscribes to the Carnegie Foundation's definition of community engagement, in practice, acts of engaging the community vary greatly and take many forms. Correspondingly, scholars continue to probe this definition's capacity "to respect the diversity of institutional contexts and approaches to engagement" (Driscoll, 2008, p. 41). Recognizing the importance of 
the language used to describe town-and-gown partnerships has become of increasing interest as institutions of higher education attempt to measure their impact (Charles, Benneworth, Conway \& Humphrey, 2010). Aligned with that trend, the goal of this article is to discuss the process employed by UNO to capture an understanding of how community engagement is conceptualized and institutionalized across the campus.

\section{The UNO Case and Broader Trends in Community Engagement Measurement}

In recent years, higher education institutions across the United States have shifted their focus by stressing the importance of assessment of community engagement initiatives and measurement of their impact ${ }^{1}$. Throughout the past decade, UNO has made significant advances in the field of community engagement. UNO was one of the original institutions to receive the Carnegie Foundation community engagement classification in 2006 and was reaffirmed as a Community Engaged institution in 2015. Furthermore, in 2014 UNO was the recipient of the Presidential Award for the Economic Opportunity category of the President's Higher Education Community Service Honor Roll. UNO has also built the state-of-the-art Barbara Weitz Community Engagement Center which is fully dedicated to advancing community engagement. These victories have heightened the desire to measure UNO's impact on the community.

While for some reporting purposes data has been collected on an ad-hoc basis at UNO, relatively little is known about the full range of community engagement activities. Similar to other higher education institutions, UNO faces difficulties in documenting and systematically gathering data about its community engagement activities, and lacks a campus-wide data tracking and assessment infrastructure (Holton, Jettner, Early \& Shaw, 2015; Holton, Early, Jettner \& Shaw, 2015; Janke \& Medlin, 2015). Other challenges facing community engagement measurement practices in higher education include: (a) a dearth of methodologies that include the perspectives and insights of various groups of stakeholders (Getto \& McCunney, 2015); (b) acquiring consensus across campus on a clear definition of community engagement (Perry, Farmer, Onder, Tanner \& Burton, 2015); and (c) capturing the multiple dimensions of community engagement (Stanton-Nichols, Hatcher \& Cecil, 2015; Kolek, 2016).

In an effort to advance the understanding of community engagement and how it is institutionalized on campus, the UNO Community Engagement Cabinet issued a charge to establish a framework for the measurement and assessment of community engagement. For UNO, community engagement is one of the campus' strategic goals with the underlying assumption being that all units incorporate community engagement into their various functions whenever possible and appropriate. However, as the campus administration made attempts to comprehend those engagement activities, the challenge became the vast array of diversity within the context of the single institution. The commonly accepted definition of community engagement is broad in its scope and limiting in its ability to guide measurement, assessment and evaluation efforts. The understanding of community engagement has inherent implications for

\footnotetext{
${ }^{1}$ See Metropolitan Universities Journal. (2015). To What End: Measuring Engagement with our Communities, 26 (2).
} 
community engagement data collection (Rosing, 2015); therefore, it was concluded that each unit's perspective must be considered in the development of a comprehensive, university-wide understanding of community engagement.

\section{Methodology}

The team tasked with creating the initial institution-wide framework for community engagement measurement and assessment quickly encountered a linguistic challenge. The term "community engagement" was used to describe and label a plethora of activities. While the term was used consistently across units, its application to activities was inconsistent. The team concluded that prior to developing measurement and assessment mechanisms the first priority was to comprehend what community engagement meant for UNO and its many offices, colleges, schools, and departments. There arose a need for a practical method of acquiring these diverse perspectives from within this large and fragmented organization. The result was a landscape analysis, a geological approach to the study of an assemblage of diverse spaces with varied "size, shape, composition, and history" (Wu \& Qi, 2000, p. 1). While there are multiple techniques for conducting these analyses, the primary aim of the approach is to produce generalized knowledge about the whole assemblage based on observations and knowledge acquired from its parts (Fahrig, 1991). Not unlike geo-spatial landscapes, universities are large organizations composed of different units with distinct purposes and a common goal, mission and/or vision. Though landscape analysis is primarily used in the hard science discipline of geology, a sociological application was the aim for this project. Because a landscape analysis is a research design and therefore amenable to a number of techniques and methods of inquiry, it is suitable for achieving the goals of this project.

The UNO landscape analysis used a purposive sampling technique, which consisted of identifying key UNO leaders, administrators, faculty, and staff who are aware of the many community engagement initiatives. Non-random sampling was used because the research design is both qualitative and exploratory (Shields \& Rangarajan, 2013). Participants were identified by the Office of Academic Affairs, which has considerable responsibility for supporting UNO's community engagement goals and is instrumental in collecting and reporting data for external community engagement award applications. Some participants were chosen based on the institutional knowledge of the Academic Affairs staff who have worked with these individuals to collect community engagement data, while others were selected based on their job title, its associated tasks, and their administrative purview.

The study also included snowball sampling as a means of identifying additional participants. At the end of each interview, participants were asked to identify others whom they felt would be able to offer additional insights about their unit's community engagement activities. For instance, deans may have a general awareness of their college's community engagement activities but someone else may handle the day-to-day operations of that college's community engagement function. The difference in perspective from general oversight to daily operations provides a more comprehensive understanding of the units' community engagement interpretation and their methods of data collection. In this first phase, 28 interviews were conducted with 32 
participants. A post-hoc analysis identified five types of participants within the sample based on characteristics of individual interviewees (i.e., responses and responsibilities) (see Table 1).

Table 1

Participant Descriptions

\begin{tabular}{|l|l|l|}
\hline Participant Type & Description & $\begin{array}{l}\text { \# of } \\
\text { Participants }\end{array}$ \\
\hline Campus Leadership & $\begin{array}{l}\text { Provide leadership and general oversight for all } \\
\text { campus divisions. }\end{array}$ & 6 \\
\hline Deans & Administrative leaders of colleges. & 8 \\
\hline Coordinators & $\begin{array}{l}\text { Work in or across units to cultivate and manage } \\
\text { partnerships with the external community. }\end{array}$ & 5 \\
\hline Frontline Implementers & $\begin{array}{l}\text { Responsible for the day-to-day oversight and } \\
\text { operations of various projects and programs within } \\
\text { a unit or division. } \\
\text { Perform a data management function (e.g., } \\
\text { collection, recording and/or retrieval) within their } \\
\text { respective unit. }\end{array}$ & 3 \\
\hline
\end{tabular}

Semi-standardized interviews were used to collect data (see Appendix A). The interview protocol asked questions about the institutionalization of community engagement at UNO as well as traditional and non-traditional community engagement data collection. The protocol was approved by the Office of Academic Affairs. It also incorporated feedback from community engagement expert Barbara Holland, Ph.D. After pilot interviews, protocols were reevaluated and the questions were simplified. Each interview was conducted with two interviewers. Protocols were modified at the discretion of the interviewers based on their perceptions of time constraints and priority of research goals.

Interviews were conducted simultaneously with two interviewers in either the participants' offices or at a location of their choosing. Immediately following each interview, the interviewers debriefed and discussed the concepts, themes and other points they felt were significant during the interview. Within forty-eight hours of each interview, field notes were compiled into one cohesive document and both interviewers conducted initial readings.

Although the interviews were the primary data source for analysis, the researchers also examined the participants' websites, each unit's mission statement if available, and follow-up documents provided by the participants. Taken together, these interview responses and other documents supplied a rich and robust text for qualitative analysis. Codes were identified based on words and phrases found within the text of each interview. The codes were taken from text based on frequency of use and relationship to other text. Text were coded by one interviewer using MAXQDA software and the analyses of the data took place in consultation with the research team. 
The data were analyzed using an inductive, open coding approach. This process began with open coding, which Berg and Lune (2012) describe as holding interpretations and answers as "tentative at best" (p. 364) until the coding is completed and they are "present in the text or supported by it" (p. 365). The thematic coding process was iterative and resulted in axial coding wherein relationships were identified and connections were made between various

codes. Multiple sources of data were used to ensure trustworthiness. This triangulation technique entails "using different methods as a check on one another" (Maxwell, 2013, p. 102). By using multiple interviewers, field notes, and document analysis, researchers attempted to mitigate the limitations of each method.

As with any research study, this study is not without its limitations. A major flaw of purposive selection is that it biases the participant sample. Although purposive sampling is desirable for this type of study, it limits the scope of perspectives. In particular, faculty, students, community and other stakeholders are not represented in these findings. Additionally, given the goals of this study, data technicians have extensive expertise; however, that group is vastly underrepresented in this sample. All of the technicians in this study were identified through snowball sampling. Although identifying other data technicians must be a priority in future research, this may present challenges: there may only be few data technicians employed, and often data technicians have titles that do not indicate any link to data collection and reporting.

\section{Findings}

As was expected, different units conceptualize community engagement differently. The following analysis provides a typology of the major themes presented in the conceptualization of community engagement. The typology includes 15 frequently occurring themes which have been divided into three domains (i.e., internal, process, criteria) (see Table 2). The themes were emphasized by various participants when asked to define and describe community engagement. The themes are products of open coding and the domains are results of the axial coding technique. Moreover, the themes and domains are not mutually exclusive. Accordingly, when speaking of community engagement, some participants used themes from one or more of the domains.

Table 2

Domains of Community Engagement

\begin{tabular}{|l|l|l|l|}
\hline \multicolumn{1}{|c|}{ Domain } & Internal & Process & Criteria \\
\hline $\begin{array}{l}\text { Engagement } \\
\text { is: }\end{array}$ & $\begin{array}{l}\text { A tool for student } \\
\text { development with } \\
\text { excess benefits to } \\
\text { others. }\end{array}$ & $\begin{array}{l}\text { Based on the conditions } \\
\text { surrounding the activity. }\end{array}$ & $\begin{array}{l}\text { Assessed based on an } \\
\text { awareness of the } \\
\text { product, its benefits and } \\
\text { the process. }\end{array}$ \\
\hline Themes & $\begin{array}{l}\text { Social } \\
\text { Interaction/Involvement } \\
\text { Social Responsibility }\end{array}$ & $\begin{array}{l}\text { Responsiveness } \\
\text { Facilitation } \\
\text { Outreach }\end{array}$ & $\begin{array}{l}\text { Reciprocal/Mutually } \\
\text { Beneficial }\end{array}$ \\
Partnership
\end{tabular}




\begin{tabular}{|l|l|l|l|}
\hline & Belonging & Access & Collaboration \\
Meaningfulness/Critical & Diversity/Inclusion & Communication \\
Thinking & & Knowledge \\
& & Development/Learning \\
& & Information and \\
& & Resource Sharing \\
\hline
\end{tabular}

Internal Domain

For some participants, community engagement has an internal focus, student focus which highlights its features and aspects. More specifically, these participants view engagement as a tool for student development with surplus benefits to the community. Of primary concern is:

- encouraging students to become active and involved citizens;

- helping students to understand that what they do is about more than just their own achievement;

- consideration for how students are growing and learning and what skills they are developing; and

- ensuring that students have an awareness of what they are learning through those experiences.

The four themes within this internal domain of community engagement are: (a) social interaction and involvement; (b) social responsibility; (c) belonging; and, (d) meaningfulness and critical thinking.

Table 3

Internal Domain

\begin{tabular}{l|l|l|}
$\begin{array}{l}\text { Internal } \\
\text { Domain }\end{array}$ & Definitions & Description \\
\hline $\begin{array}{l}\text { Social } \\
\text { Interaction/ } \\
\text { Involvement }\end{array}$ & $\begin{array}{l}\text { Activities that provide } \\
\text { opportunities for participants to } \\
\text { engage with others, preferably a } \\
\text { diverse group of people. }\end{array}$ & $\begin{array}{l}\text { "They're meeting new people. They } \\
\text { understand that they're helping the } \\
\text { world in doing this" (Participant 18). }\end{array}$ \\
\hline $\begin{array}{l}\text { Social } \\
\text { Responsibility }\end{array}$ & $\begin{array}{l}\text { Activities that emphasize the } \\
\text { importance of creating a sense of } \\
\text { accountability; a commitment to a } \\
\text { group or cause outside of one's } \\
\text { self. }\end{array}$ & $\begin{array}{l}\text { "It's not just about learning material } \\
\text { and books and stuff, it's about learning } \\
\text { how to exist in a much larger world } \\
\text { where, hopefully, we are all working } \\
\text { towards a greater good" (Participant }\end{array}$ \\
\hline Belonging & $\begin{array}{l}\text { Activities that facilitate an } \\
\text { students' understanding as being } \\
\text { part of her/his community or } \\
\text { member of a larger group. }\end{array}$ & $\begin{array}{l}\text { 15). } \\
\text { "Community engagement is a sense of } \\
\text { belonging. In some ways shared } \\
\text { existence and also a sense of reason for } \\
\text { that, like wanting to be with these other }\end{array}$ \\
\hline
\end{tabular}




\begin{tabular}{|l|l|l|}
\hline & $\begin{array}{l}\text { people... [Students] need to find a safe } \\
\text { [emphasizes sense of place] }\end{array}$ & $\begin{array}{l}\text { place to be in a community that will } \\
\text { validate what they are doing, who they } \\
\text { are becoming" (Participant 18). }\end{array}$ \\
\hline $\begin{array}{l}\text { Meaningfulness/ } \\
\text { Critical } \\
\text { Thinking }\end{array}$ & $\begin{array}{l}\text { Activities that promote and } \\
\text { facilitate reflection where } \\
\text { students are becoming aware of } \\
\text { the impact of a contribution. }\end{array}$ & $\begin{array}{l}\text { local and global communities" } \\
\text { (Participant 23). }\end{array}$ \\
\hline
\end{tabular}

Process Domain

When asked to define and give examples of community engagement, some participants emphasize the driving forces behind engagement. These participants speak of the process of community engagement. In these instances, engagement is defined based on the conditions surrounding the activity, which include: responsiveness, facilitation, outreach, access, and diversity/inclusion.

Table 4

Process Domain

\begin{tabular}{|c|c|c|}
\hline $\begin{array}{l}\text { Process } \\
\text { Domain }\end{array}$ & Definition & Description \\
\hline Responsiveness & $\begin{array}{l}\text { Address the changing needs of } \\
\text { a community. }\end{array}$ & $\begin{array}{l}\text { Community engagement requires } \\
\text { colleges and universities to be attentive } \\
\text { to what is going on around them. It } \\
\text { requires them to be receptive to } \\
\text { community needs, then and only then } \\
\text { can they assure that they remain relevant } \\
\text { within a society. It also means } \\
\text { recognizing that yesterday's, today's and } \\
\text { tomorrow's goals may not be the same } \\
\text { because those needs change. } \\
\text { (Participants } 5,7 \text {, and } 27 \text { ) }\end{array}$ \\
\hline Facilitation & $\begin{array}{l}\text { Survive as a conduit to } \\
\text { encourage the coming together } \\
\text { of people to solve issues. }\end{array}$ & $\begin{array}{l}\text { "We provide a safe space that allows } \\
\text { people to come together, express how } \\
\text { they feel, generate new ideas and settle } \\
\text { disagreements" (Participant 13). }\end{array}$ \\
\hline Outreach & $\begin{array}{l}\text { Actively working to build } \\
\text { relationships with audiences } \\
\text { external to the campus. }\end{array}$ & $\begin{array}{l}\text { "Getting UNO students, faculty and staff } \\
\text { to be involved outside in the community } \\
\text { and what they are doing" (Participant } \\
\text { 13). }\end{array}$ \\
\hline
\end{tabular}




\begin{tabular}{|l|l|l|}
\hline & $\begin{array}{l}\text { "It involves educating others about what } \\
\text { we are about, so they know, what we do, } \\
\text { what we have to offer, and why it is } \\
\text { important." (Participant 8) }\end{array}$ \\
\hline Access & $\begin{array}{l}\text { Intentionally designating and/or } \\
\text { using university spaces and } \\
\text { making university resources } \\
\text { available for the use and } \\
\text { enjoyment of external } \\
\text { audiences. }\end{array}$ & $\begin{array}{l}\text { In order to be engaged, we need to make } \\
\text { our campus open and available for the } \\
\text { community to come in and work and } \\
\text { collaborate. (Participants 11 and 13) }\end{array}$ \\
\hline $\begin{array}{l}\text { Ensuring representation of a } \\
\text { broad-range of opinions/ideas } \\
\text { and audiences. }\end{array}$ & $\begin{array}{l}\text { "In order to solve community problems } \\
\text { we need to draw and use a wide range of } \\
\text { Inclusion }\end{array}$ & $\begin{array}{l}\text { audiences and expertise" (Participant } \\
11) .\end{array}$ \\
\hline [emphasis placed on people] & & \\
\hline
\end{tabular}

Criteria Domain

The third group focuses on the criteria for engagement. For this group, engagement is assessed based on an awareness of the product, its benefits, and the process whereby it was created. Here, if the outcomes meet certain criteria, then the activity is considered community engagement.

Table 5

Criteria Domain

\begin{tabular}{|c|c|c|}
\hline Criteria Domain & Definition & Description \\
\hline $\begin{array}{l}\text { Reciprocal/ } \\
\text { Mutually } \\
\text { Beneficial }\end{array}$ & $\begin{array}{l}\text { Equity in benefits and burdens } \\
\text { among stakeholders. }\end{array}$ & $\begin{array}{l}\text { "It's about both giving back to those } \\
\text { who have given to us and providing a } \\
\text { benefit for everyone" (Participant 2). } \\
\text { "It's doing work with rather than to } \\
\text { or for" (Participants 28). }\end{array}$ \\
\hline Partnership & $\begin{array}{l}\text { A relationship in which all } \\
\text { stakeholders have equal status, } \\
\text { rights and opportunities. }\end{array}$ & $\begin{array}{l}\text { "I think engagement is successful } \\
\text { when everybody feels like they are } \\
\text { included - and actually bring things } \\
\text { to the table when we initiate efforts } \\
\text { and stuff... So for us engagement is } \\
\text { really defined by a very active role of } \\
\text { the partners" (Participant 16). }\end{array}$ \\
\hline Collaboration & $\begin{array}{l}\text { Intentionally and strategically } \\
\text { working together to produce a }\end{array}$ & $\begin{array}{l}\text { "We have to constantly find new } \\
\text { ways for different people and } \\
\text { organizations to come together" } \\
\text { (Participant 12). }\end{array}$ \\
\hline
\end{tabular}




\begin{tabular}{|c|c|c|}
\hline & $\begin{array}{l}\text { desired and agreed-upon } \\
\text { outcome. } \\
\text { [emphasis on the mode or } \\
\text { method of coming together] }\end{array}$ & \\
\hline Communication & $\begin{array}{l}\text { Sharing ideas and feelings } \\
\text { among stakeholders. }\end{array}$ & $\begin{array}{l}\text { "It entails clarifying goals among all } \\
\text { stakeholders" (Participant 21). }\end{array}$ \\
\hline $\begin{array}{l}\text { Knowledge } \\
\text { Development/ } \\
\text { Learning }\end{array}$ & $\begin{array}{l}\text { Opportunities to apply } \\
\text { knowledge and/or develop some } \\
\text { new understanding of a } \\
\text { phenomenon or its context. }\end{array}$ & $\begin{array}{l}\text { "It's about the application of } \\
\text { knowledge, not just pure discovery" } \\
\text { (Participant } 7 \text { ). }\end{array}$ \\
\hline $\begin{array}{l}\text { Information and } \\
\text { Resource } \\
\text { Sharing }\end{array}$ & $\begin{array}{l}\text { Promote open access to } \\
\text { knowledge. }\end{array}$ & $\begin{array}{l}\text { "Alignment of university resources } \\
\text { and community needs" (Participant } \\
\text { 26). } \\
\text { This also entails making scholarship } \\
\text { and research available. (Participant } \\
\text { 9). } \\
\text { "Bridging the gap between campus } \\
\text { and community. It is about how to } \\
\text { connect campus, research, resources, } \\
\text { faculty, and staff to the community } \\
\text { and vice versa" (Participant 12). }\end{array}$ \\
\hline
\end{tabular}

In addition to this newfound understanding of the domains of engagement, further analysis of participant responses to the second set of interview questions about community engagement data illustrated the following:

1. Across campus, participants define and conceptualize in varied ways.

2. The term community engagement is used across campus to refer to both service as well as the (technical) Carnegie definition of community engagement.

3. Some participants expressed frustration when they perceived their work was not fully appreciated as community engagement.

4. Senior administrators have consistently expressed value of all types of engagement, referring to both traditionally 'service' and 'volunteerism' activities, as well as curricular engagement.

5. Participants involved with predominantly service activities placed a strong emphasize on the importance of reflection and learning. 
These specific findings led to the spectrum of community engagement, which is discussed in the following section. There we argue that service and the technical definition of community engagement are part of the same spectrum. All activities aimed at engaging the external community for the purpose of advancing the public good are part of this spectrum. Both ends of the spectrum are valued, although it is recognized that specific aspects of the technical definition of engagement yield a higher return on investment. Additionally, specific changes in project design can move service activities more towards the technical engagement side (e.g. purposeful reflections).

The aforementioned domains and their subordinate themes directly relate to the descriptions provided by the participants when capturing the essence of community engagement. It is believed that the spectrum of community engagement can be further developed into a matrix, and the domains and themes derived from this research should inform the matrix to ensure alignment in terminology and language.

\section{Discussion}

Parallel to other higher education institutions, there is no uniformity to the conceptualization of the term 'community engagement' at UNO. Community engagement reflects a dichotomous view in which 'community service' and 'community engagement' are considered two separate principles. At UNO, value is ascribed to both service and engagement. Service is considered as done to or for a community, whereas engagement is aligned with the Carnegie Foundation's definition and is done with a community.

An analysis of the data suggests moving into an understanding that the label 'Community Engagement', as used in various institutional documents, refers to a spectrum which incorporates service on one end of the spectrum and community engagement (as defined by the Carnegie Foundation) on the other end of the spectrum (see Figure 1). There is, therefore, a difference between the commonly-used label of community engagement and the technical definition of community engagement.

\section{Community Engagement (label)}

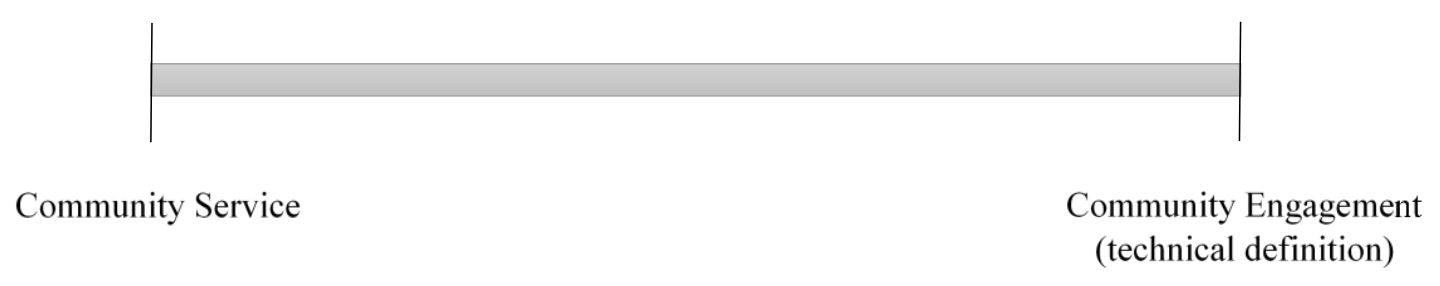

Figure 1.

By making this distinction explicit, the institution takes a more inclusive approach to the practice of community engagement, which reiterates the value for all service and engagement activities. Further, this nuanced understanding of community engagement provides the institution with an opportunity to engage in project design conversations which could move community service 
activities towards community engagement. Rather than taking a zero-sum approach, activities can fall anywhere on the community engagement spectrum, and relatively simple project design changes would allow community service activities to move towards community engagementwhich deriving from the findings, is the desired trend and outcome. For instance, curricular engagement by nature is more aligned with the technical definition of community engagement. Interestingly, divisions that are traditionally more aligned with 'service', such as Athletics and Student Affairs, are taking intentional project design steps towards 'community engagement'. Examples are the intentional focus on student reflections (Athletics) and the incorporation of cocurricular assessment plans (Student Affairs).

The community engagement spectrum is an aggregate-level depiction of various community engagement dimensions, including:

- context (need)

- knowledge (learning, reflection, exchange of information)

- outcome (product, benefit, impact)

- operation (transactional, space, resources)

These dimensions can be structured into a matrix, in which each dimension is rated, based on the extent it correlates to various levels of community engagement (technical) criteria. Further, these dimensions are important components in the project design of community engagement initiatives. In recognizing that the gains associated with the technical definition of community engagement are higher, the university can engage in conversations on how to make intentional changes in the process/project design that would allow the project to be elevated to engagement. Although external versions of the community engagement spectrum exist, it is important not to impose an external matrix on an institution, but rather to have the spectrum and the matrix emerge from within one's own institution. This will allow the institution to incorporate the terminologies and themes used across campus, which will increase campus buy-in to the matrix while providing ownership and accountability.

\section{Community Engagement (label)}

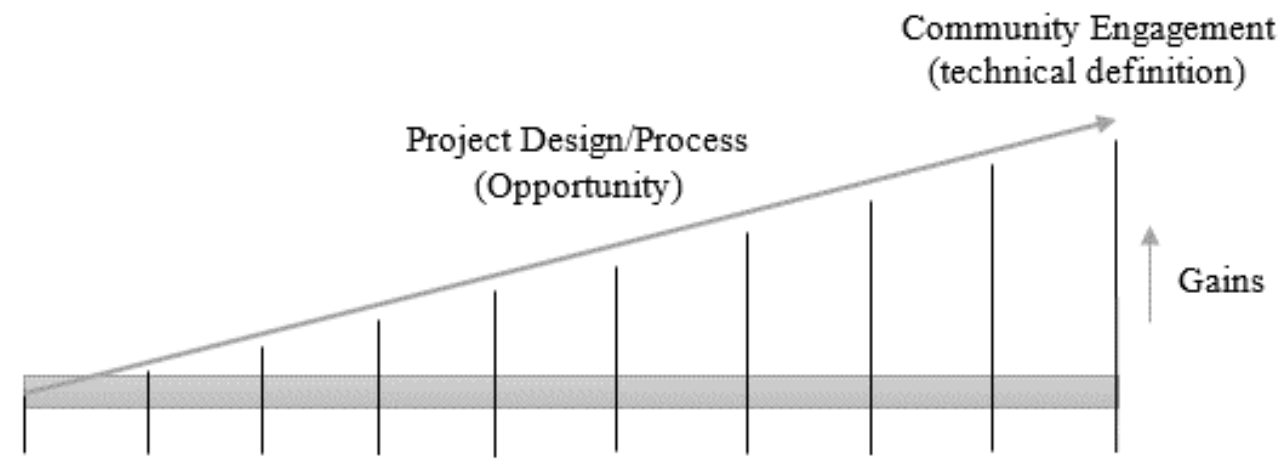

\section{Community Service}

Figure 2.

Project Design/Process 
A crucial benefit in the proposed community engagement spectrum approach is the institution's ability to leverage project design and processes as mechanisms to elevate activities to higher levels of engagement. Analysis of the data indicates that the existence of active external partner(s) is a criterion for the institution to engage in this process. For example, community service can be conducted without collaboration with an active external partner (e.g. students donating food items to a food pantry). Although the partnership does not need to be formalized, its existence is a prerequisite in the institution's ability to elevate service activities towards engagement. After all, the essence of community engagement (technical) lies in it being done with rather than to or for the community, which by definition forces the partner to play an active role in community engagement.

This increased level of collaboration with a community partner is an important component of the project/process design that can be leveraged to raise community service to community engagement. Alterations to the project design/process would have the following implications for the earlier identified matrix dimensions:

- Context

○ To what extent is the need/problem/issue/project identified through mutual decision-making?

○ To what extent does the need/problem/issue/project reflect the diverse perspectives of the various partners?

- Knowledge

- Are all partners active participants in knowledge production?

$\circ$ Is active reflection and learning occurring?

- Outcome

- Are all stakeholders benefitting/impacted?

\section{- Operation}

- Are all partners actively involved in the various aspects of the project?

$\circ$ To what extent are partners working together on the various aspects of the project?

Building upon the previous example of students donating food items to the food pantry, once a partnership between the university and an external community organization is embraced (e.g. the local food pantry). Simple collaborations will allow this act of service to move towards engagement. For instance, instead of a one-dimensional relationship where students donate food items, a representative from the food pantry could educate students on issues surrounding hunger. This simple change in project design will increase the benefits for both students and the community partner, and take the project a small step towards engagement.

\section{Conclusion}

The obstacle that lay ahead of the project team was, in essence, a linguistic challenge. The extant literature on community engagement offered a definition of community engagement that was too ambiguous to provide clear guidelines and boundaries for developing all-encompassing measurement and assessment strategies. In practice, community engagement had become an 
ambiguous term at UNO, used by all while meaning different things to different people. The landscape analysis found that at a conceptual level, different stakeholders were using the term to speak of various facets of the many activities they consider to be community engagement. Thus, the objective here is not to redefine community engagement, rather it is to grasp how stakeholders are using the term and what attributes they use to identify the perceived essence of the term community engagement.

Conducting a landscape analysis has been the equivalent of a 'pulse check' for UNO, providing in-depth insight on the various perspectives about community engagement across the university. This is a prudent imperative, given the status of community engagement as one of the campus' strategic goals. As an approach to inquiry, the landscape analysis allows the university to critically reflect on the current state of its community engagement and take deliberate and informed action to strengthen those efforts. Moreover, the approach is both neutral and exploratory. Strategic research design elements, including semi-standardized interviews, selection of interviewers, use of multiple interviewers, purposive and snowball sampling techniques, and the provisional nature of the interview protocol resulted in rich data.

Furthermore, the findings presented in this article have provided a firm foundation for future research regarding community engagement measurement and assessment. By broadening the scope of the university's definition of engagement - and mining the nuances in uses of the term 'community engagement' - the university is better positioned to operationalize the construct and develop measures. Drawing on existing knowledge of community engagement, this research builds upon the campus' current conceptions and practices. The discovery of domains of engagement has established a common language that tears down the walls which once existed between units and disciplines. The domains of engagement help solve this linguistic dilemma by providing a lexicon of more precise attributes of community engagement. The spectrum of engagement is a conceptual tool that gives greater understanding to the nuances of engagement. It delivers a method for modifying and transforming service projects that desire to be more engaged.

Though not discussed in this article, the landscape analysis enhanced UNO's overall knowledge of community engagement data. It has allowed the university to re-examine existing data sources. It has also allowed UNO to map data sources which were believed to exist of which lacked concrete awareness. Further, the landscape analysis exposed the existence of data of which there was no prior knowledge. Based on the recommendations from the landscape analysis, the UNO Community Engagement Cabinet commissioned a Community Engagement Measurement Group made up of representatives from multiple units. This group is tasked with facilitating data collection, analysis, and reporting - including developing rubrics and metrics for categories along the engagement spectrum.

The only effective communication is shared meaning. As a result of this landscape analysis, the university has begun a critical dialogue to understand the many understandings of community engagement across campus. Whereas other institutions are likely to discover different themes and domains after conducting a landscape analysis, this method of inquiry still provides an approach for starting a fruitful dialogue. 


\section{References}

Berg, B.L. \& Lune, H. (2012). Qualitative research methods for the social sciences. Upper CA: SAGE.

Charles, D., Benneworth, P., Conway, C. \& Humphrey, L. (2010). How to benchmark university-community interactions. In P. Inman \& H. G. Schuetze (Eds.), The Community Engagement and Service Mission of Universities (p. 69-85). Leicester, UK: National Institute of Adult Continuing Education.

Committee on Institutional Cooperation. (2005). Engaged scholarship: A resource guide. Washington, DC.

Driscoll, A. (2008). Carnegie's community-engagement classification: Intentions and insights. Change: The Magazine of Higher Learning, 40(1), 38-41. https://dx.doi.org/10.3200/CHNG.40.1.38-41

Getto, G. \& McCunney, D. (2015). Inclusive assessment: Toward a socially-just methodology for measuring institution-wide engagement. Metropolitan Universities Journal, 26(2), 923. Retrieved from https://journals.iupui.edu/index.php/muj/article/view/20976

Holton, V.L., Early, J.L., Jettner, J.F. \& Shaw, K.K. (2015). Measuring community-university partnerships across a complex research university: Lessons and findings from a pilot enterprise data collection mechanism. Metropolitan Universities Journal, 26(2), p. 99123. Retrieved from https://journals.iupui.edu/index.php/muj/article/view/20980

Holton, V.L., Jettner, J.F., Early, J.L. \& Shaw, K.K. (2015). Leveraging internal partnerships and existing data infrastructure to track and assess community engagement across the university. Metropolitan Universities Journal, 26(2), p. 75-98. Retrieved from https://journals.iupui.edu/index.php/muj/article/view/20979

Janke, E.M. \& Medlin, K.D. (2015). A centralized strategy to collect comprehensive institutionwide data from faculty and staff about community engagement and public service. Metropolitan Universities Journal, 26(2), p. 125-146. Retrieved from https://journals.iupui.edu/index.php/muj/article/view/20981

Kolek, E. (2016. Measurement matters: Estimating students' community engagement participation. International Journal of Research on Service-Learning and Community Engagement, 4(1), 29-37. Retrieved from http://journals.sfu.ca/iarslce/index.php/journal/article/view/22

Maxwell, J.A. (2013). Qualitative research design: An interactive approach. Thousand Oaks, CA: SAGE 
New England Resource Center for Higher Education. (2017). Carnegie community engagement classification. Retrieved from http://nerche.org/index.php?option=com_content\&view=article\&id=341\&Itemid=92

Perry, L., Farmer, B., Onder, D., Tanner, B. \& Burton, C. (2015). A community-based activities survey: Systematically determining the impact on and of faculty. Metropolitan Universities Journal, 26(2), p. 25-45. Retrieved from https://journals.iupui.edu/index.php/muj/article/view/20977

Rosing, H. (2015). Tracking culture: The meanings of community engagement data collection in higher education. Journal of Metropolitan Universities, 26(2), p. 147-163. Retrieved from https://journals.iupui.edu/index.php/muj/article/view/20982

Shields, P. M., \& Rangarajan, N. (2013). A playbook for research methods: Integrating conceptual frameworks and project management. Stillwater, OK: New Forums Press.

Stanton-Nichols, K., Hatcher, J. \& Cecil, A. (2015). Deepening the institutionalization of service-learning: The added value of assessing the social return of investment. Metropolitan Universities Journal, 26(2), p. 47-74 Retrieved from https://journals.iupui.edu/index.php/muj/article/view/20978

Turner, M. G., \& Gardner, R. H. (Eds.). (1991). Quantitative methods in landscape ecology (p. 536). New York, NY: Springer Verlag. https://dx.doi.org/10.1007/978-1-4757-4244-2

University of Nebraska at Omaha. (2012). Campus strategic plan. Omaha, NE. Retrieved from http://www.unomaha.edu/plan/our_plan.php

Wu, J. \& Qi, Y. (2000) Dealing with scale in landscape analysis: An overview. Geographic Information Sciences, 6(1), p. 1-5. https://dx.doi.org/10.1080/10824000009480528 


\section{Appendix A}

Part I: Institutionalization of Community Engagement

1. How does your unit both conceptualize and actualize community engagement?

a. What does community engagement mean in your unit?

b. To what extent is this reflected in your unit's mission/vision?

c. What criteria do you use to identify engagement?

d. Are there faculty, staff, or students in your unit that exemplify a commitment to community engagement?

2. Does the unit have adequate infrastructure to support community engagement? Please explain.

3. Are there incentives and rewards that support faculty in community engagement?

a. Is the ability to lead in the community engagement arena a criteria for the selection and evaluation of unit leaders, considered in tenure and promotion decisions, faculty/staff recruitment and/or staff evaluations?

4. Is community engagement built into the curriculum?

a. Are there courses that regularly/always include a community experience (e.g., practicum, internship, capstone, etc.)?

5. In your day-to-day operations, is community engagement part of your unit?

a. Are the unit's faculty/staff and students active and visible in the community's educational, civic, and cultural life?

b. Is it based on the discretion of the faculty member?

c. To what extent is the unit's leadership encouraging the addition of a community engagement component? 
Part II: Community Engagement Traditional and Untraditional Data Collection

1. What types of community engagement activities are your students and faculty undertaking?

2. Does your unit keep track of these activities?

a. If yes, what types of information are you gathering?

b. How is it being recorded?

c. Is this information gathered on an ad hoc/sporadic basis or is it more regular/systematic.

3. What types/specific reports are you generated based on this information?

a. What do you do with these reports - what is their purpose?

b. Are there specific reports or types of report you want to generate, that you are currently unable to generate?

i. What type of information would you need

ii. Suggestions as to where we should begin to start collecting this information?

4. What information do you think others are gathering, that might be relevant for our research?

5. In what ways can the Office of Academic Affairs improve sharing or highlighting your unit's community engagement?

a. How can we go about making sure that the Office of Academic Affairs is aware of this information?

Final Question

6. Is there anyone else that you would suggest we talk to, in order to gain a better understanding of your unit's community engagement activities? 


\section{Author Information}

Anthony Starke, MPA, is a doctoral student at the University of Nebraska at Omaha. Anthony holds Bachelor of Science degrees in Psychology and Human Services from Old Dominion University as well as a graduate certificate in Nonprofit Management and Master of Public Administration degree from Virginia Commonwealth University. Anthony works as graduate research assistant for the UNO Office of Academic Affairs where he assists with measurement, assessment, evaluation and research pertaining to university-wide community engagement.

Anthony M. Starke, Jr.

University of Nebraska at Omaha

6001 Dodge Street, CPACS 113B

Omaha, NE 68182

E-mail: astarke@unomaha.edu

Telephone: 402-554-2773

Keristiena Shenouda, MSc, is a project specialist at the Office of Academic Affairs. She leads the community engagement measurement and assessment group. Keristiena is also responsible for community engagement reporting, data gathering/analysis, and award applications. She holds a master's degree from the University of London.

Keristiena Shenouda

University of Nebraska at Omaha

6001 Dodge Street, EAB 203

Omaha, NE 68182

E-mail: kshenouda@unomaha.edu

Telephone: 402-554-2364

Deborah Smith-Howell, Ph.D., is the associate vice chancellor of academic affairs and the dean of graduate studies. Dr. Smith-Howell is a member of the UNO engagement cabinet and has administrative oversight over the Service Learning Academy and community engagement reporting. She holds a Ph.D. from the University of Texas.

Deborah Smith Howell*

University of Nebraska at Omaha

6001 Dodge Street

Omaha, NE 68182

E-mail: dsmith-howell@unomaha.edu

Telephone: 402-554-4849

*corresponding author 